Research Paper

\title{
The Relationship of Serum Antigen-Specific and Total Immunoglobulin E with Adult Cardiovascular Diseases
}

\author{
Zhiyan $\mathrm{Xu}^{1,2^{*}}$, Tao $\mathrm{Wang}^{3 *}$, Xiaoxiao $\mathrm{Guo}^{4}$, Yao $\mathrm{Li}^{1}$, $\mathrm{Yi} \mathrm{Hu}^{5}$, Chao $\mathrm{Ma}^{2}{ }^{凶}$, Jing Wang ${ }^{1 凶}$ \\ 1. Department of Pathophysiology, State Key Laboratory of Medical Molecular Biology, Peking Union Medical College, Beijing, China \\ 2. Department of Anatomy, Histology and Embryology; Institute of Basic Medical Sciences, Chinese Academy of Medical Sciences, Peking Union Medical \\ College, Beijing, China. \\ 3. Department of Neurosurgery, Xuanwu Hospital, Capital Medical University, Beijing, China. \\ 4. Department of Cardiology, Peking Union Medical College Hospital, Peking Union Medical College and Chinese Academy of Medical Sciences, Beijing, \\ China \\ 5. CAS Key Laboratory for Biomedical Effects of Nanomaterials and Nanosafety, Multi-disciplinary Research Division, Institute of High Energy Physics, \\ Chinese Academy of Sciences (CAS), Beijing, China. \\ *Zhiyan Xu and Tao Wang contributed equally to this article.
}

$\square$ Corresponding authors: Institute of Basic Medical Sciences, Chinese Academy of Medical Sciences, No. 5 Dongdansantiao, Beijing, China, 100005. Email address: wangjing@ibms.pumc.edu.cn (J. Wang); machao@ibms.cams.cn (C. Ma)

(c) Ivyspring International Publisher. This is an open access article distributed under the terms of the Creative Commons Attribution (CC BY-NC) license (https://creativecommons.org/licenses/by-nc/4.0/). See http://ivyspring.com/terms for full terms and conditions.

Received: 2018.03.04; Accepted: 2018.05.22; Published: 2018.07.01

\begin{abstract}
Background: The relationship of serum antigen-specific immunoglobulin E (IgE) with cardiovascular diseases (CVDs) remains poorly understood. This study aimed to explore the association of antigen-specific and total IgE with CVDs using data derived from the National Health and Nutrition Examination Survey (NHANES) 2005-2006.

Methods and Results: The association of serum total or antigen-specific IgE levels with CVDs was analyzed by survey-weighted logistic regression modeling, adjusted by age, sex, race, education, body mass index, blood pressure, total cholesterol, C-reactive protein, homocysteine, diabetes, smoking, and alcohol consumption. 4953 subjects were included. Coronary heart disease was significantly related to serum total IgE levels. The association of serum total IgE levels with coronary heart disease was further validated by negative, $\geq 1$ and 1-6 positive antigen-specific lgE. Myocardial infarction was positively associated with serum total IgE levels only when all antigen-specific lgE were negative, but inversely associated with serum total IgE when plant-specific IgE test results were positive. More specifically, myocardial infarction was also inversely related to positive oak, birch, or peanut-specific lgE. In addition, serum total lgE are positively associated with angina when at least one specific IgE were positive.

Conclusions: Serum antigen-specific $\lg \mathrm{E}$, as well as total $\lg \mathrm{E}$, is significantly associated with CVDs independently of a long list of established cardiovascular risk factors, which is more informative than total IgE per se.
\end{abstract}

Key words: Immunoglobulin E; Antigen-specific IgE; Cardiovascular diseases; Immune system

\section{Introduction}

Cardiovascular diseases (CVDs) are disorders of the heart and blood vessels which mainly include coronary heart disease (CHD), cerebrovascular disease, peripheral artery disease, rheumatic heart disease, congenital heart disease, and other related conditions $^{1}$. An estimated 17.5 million people died from CVDs in 2012, representing 31\% of all global deaths, which makes CVDs the number one cause of death globally and world's major disease burden 1,2 .
Of these CVDs-related deaths, an estimated 7.4 million were due to coronary heart disease and 6.7 million were due to stroke ${ }^{1}$. The five leading preventable risk factors for CVDs are hypercholesterolemia, diabetes, hypertension, obesity and smoking, which were estimated to account for the majority of deaths from CVDs ${ }^{3}$. Over 90 percent of coronary heart diseases occurred in individuals with at least one risk factor, while much few events occurred in 
patients with no major risk factors ${ }^{4-6}$. Most of the established risk factors for CVDs are modifiable by specific preventive ways, and identification of novel risk factors for CVDs is of great importance to better prevention and management of the diseases ${ }^{3}$.

Immunoglobulins E (IgEs) are a group of immunoglobulins synthesized and released by $\mathrm{B}$ lymphocytes and act as one of the key components involved in the immune response to an allergen, which is called type I hypersensitivity ${ }^{7}$. The relationship between total IgE and CVDs was first studied and reported by Criqui et al. in 1987 . This cross-sectional study including 577 subjects (262 men and 315 women, aged 38 to $82 \mathrm{yr}$ ) showed that the mean total IgE levels were 1.2-fold $(p<0.05)$ higher in men who had a previous history of acute myocardial infarction (AMI) compared to those who didn't ${ }^{8}$. Further studies by others indicated that high serum IgE levels might be related to myocardial infarction, coronary arterial disease, cerebral arterial stenosis, coronary artery aneurysms and other CVDs 9-14. Furthermore, we and our colleagues found that serum IgE levels were significantly higher in multi-vessel disease compared to single-vessel disease (61.80 vs. $32.45 \mathrm{kU} / \mathrm{L}, p=0.003$ ) independently of traditional cardiovascular risk factors, indicating that serum IgE levels might be associated with coronary artery disease severity ${ }^{15}$. Another study reported by us showed that IgE was able to stimulate arterial cell apoptosis and cytokine expression and promote atherosclerosis by enhancing $\mathrm{Na}+/ \mathrm{H}+$ exchanger 1 (NHE1) activity on macrophages ${ }^{16}$. However, unlike total serum IgE, the association of antigen-specific $\operatorname{IgE}$ with CVDs was rarely studied ${ }^{17}$. The goal for the present study was to explore the relationship between IgE and CVDs with emphasis on antigen-specific IgEs using data from the National Health and Nutrition Examination Survey (NHANES) 2005-2006.

\section{Materials and methods}

\section{Study population}

NHANES has been a national, population-based, multi-year, cross-sectional study in the United States. It used a stratified, multistage probability design to sample the civilian, non-institutionalized household population of the US. In the NHANES 2005-2006, low-income subjects, adolescents (12-19 years of age), elderly subjects ( $\geq 60$ years of age), African Americans and Mexican Americans were oversampled among others. NHANES 2005-2006 was approved by the National Center for Health Statistics, Centers for Disease Control and Prevention, Institutional Review Board, and written informed consents were obtained from all subjects aged 18 and above. Since subjects aged less than 20 were not asked in relation to cardiovascular disease conditions, we limited the study population to subjects aged 20 and above in the analysis. Data obtained from NHANES 2005-2006 are free for public use and available online (http:// wwwn.cdc.gov/Nchs/Nhanes/Search/nhanes05_06. aspx).

\section{Assessment of CVDs}

The CVDs questionnaire, a part of routine component in the medical conditions section, provides self-reported CVDs-related outcomes, including congestive heart failure, coronary heart disease, angina, heart attack and stroke. Current or past CVD status was ascertained with affirmative answers to the following questions: Has a doctor or other health professional ever told you that you had congestive heart failure/coronary heart disease/ angina/heart attack/stroke? Subjects who had at least one positive answer for coronary heart disease (Reported in the original survey without further specification), angina, or heart attack were considered as patients with coronary heart disease (CHD). Patients with angina, myocardial infarction (heart attack) or stroke were defined by exclusively positive answer for angina, heart attack, and stroke, respectively. Subjects who had at least one positive answer for the five questions described above were collectively defined as patients with CVDs. Detailed description and results for the CVDs questionnaire can be found online (http://wwwn.cdc.gov/Nchs/ Nhanes/2005-2006/MCQ_D.htm).

\section{Measurement of serum total and allergen-specific IgEs}

Serum total and 19 allergen-specific $\operatorname{IgE}$ antibodies were analyzed with the Pharmacia Diagnostics ImmunoCAP 1000 System (Kalamazoo, Michigan, USA). Specific IgE levels were measured against six plant-related allergens (ragweed, rye grass, Bermuda grass, oak, birch and thistle), five animal-related allergens (mouse, rat, cat, dog and cockroach), four food allergens (egg white, cow's milk, peanut and shrimp), two mold-related allergens (Alternaria alternate and Aspergillus fumigatus) and two dust mite-related allergens (Dermatophagoides farinae and Dermatophagoides pteronyssinus). The lower limits of detection were $2.00 \mathrm{kU} / \mathrm{L}$ for total $\mathrm{IgE}$ and 0.35 $\mathrm{kU} / \mathrm{L}$ for each type of allergen-specific IgE. For samples below the detection limit, NHANES reported fill values equal to the lower limit of detection divided by the square root of two. No upper limit of detection reported in the total serum $\operatorname{IgE}$ assays. For the allergen-specific IgE, samples that exceeded the upper limit of detection of $1000 \mathrm{kU} / \mathrm{L}$ were assigned a value 
of $1000 \mathrm{kU} / \mathrm{L}$. High total IgE level was defined as a total IgE level of $175 \mathrm{kU} / \mathrm{L}$ or greater, and positive allergen-specific IgE was defined as $0.35 \mathrm{kU} / \mathrm{L}$ or greater. A detailed description of the laboratory method used can be found at NHANES 2005-2006 web page (http://wwwn.cdc.gov/Nchs/Nhanes/ 2005-2006/AL_IGE_D.htm).

\section{Other study measures}

Age, sex, race, education, diabetes, smoking, alcohol consumption, body mass index (BMI), blood pressure, LDL-cholesterol, HDL-cholesterol, C-reactive protein and homocysteine levels were considered as potential confounders in the analysis. Age, sex, race, education (cutoff: high school), diabetes, smoking (current smokers currently smoke cigarettes; past smokers smoked at least 100 cigarettes in life but don't smoke at all now) and alcohol consumption ( $\geq 12$ alcohol drinks/1 yr) were self-reported in questionnaires. BMI and blood pressure (cutoff: $140 \mathrm{mmHg}$ for systolic blood pressure and $90 \mathrm{mmHg}$ for diastolic blood pressure) were both measured by physical examinations. Serum LDL-cholesterol, HDL-cholesterol, C-reactive protein, and homocysteine levels were based on laboratory tests. Details of the method used for obtaining the above data can be found at NHANES 2005-2006 web page (http://wwwn.cdc. gov/Nchs/Nhanes/Search/nhanes05_06.aspx).

\section{Statistical analysis}

Statistical analysis was performed with SAS 9.4 (TS level 1M2; Cary, NC, USA). Demographic characteristics of the included participants across populations with or without CVDs were analyzed by Chi-square test or $t$ test. The same method was applied to analysis of serum total IgE levels and all other study measures. As distributions of total and antigen-specific IgE, C-reactive protein, and homocysteine levels were highly right-skewed, they were all logarithmically transformed (base 10) for statistical analyses. The association of serum total or antigen-specific IgE levels and CVDs was analyzed by survey-weighted logistic regression modeling, adjusted by age, sex, race, education, body mass index, blood pressure, total cholesterol, C-reactive protein, homocysteine, diabetes, smoking and alcohol consumption. The sampling weights (WTMEC2YR) and design variables (SDMVSTRA; SDMVPSU) were applied to these survey sampling procedures.

\section{Results}

\section{Characteristics of the included population}

Characteristics of the included participants were presented in Table 1. Samples from a total of 4953 participants, 561 (11.3\%) with CVDs and 4392 (88.7\%) without CVDs, were analyzed in this study. Among 561 patients with CVDs, 215 (38.3\%) were reported with myocardial infarction, $155(27.6 \%)$ with angina and $200(35.7 \%)$ were reported with CHD without further specification. Patients with at least one of the above three subgroups of CVDs were collectively considered as CHD patients ( $\mathrm{n}=383,68.3 \%) .193$ $(34.4 \%)$ patients were reported with stroke. In subjects with non-CVD, positive antigen-specific IgE results were more prevalent $(41.5 \%)$, compared to $31.0 \%$ in CVD group. No significant differences in ratios of high total IgE levels (cutoff: $175 \mathrm{kU} / \mathrm{L}$ ) and serum total IgE concentrations between CVD and non-CVD groups were found.

Table 1. Characteristics of the participants $(\mathrm{N}=4953)$.

\begin{tabular}{|c|c|c|c|}
\hline Characteristics & $\begin{array}{l}\text { CVD } \\
(\mathrm{N}=561 \text {, } \\
11.3 \%)\end{array}$ & $\begin{array}{l}\text { Non-CVD } \\
(\mathrm{N}=4392, \\
88.7 \%)\end{array}$ & p value \\
\hline Age (mean $\pm S D)$ & $68.1 \pm 14.2$ & $45.7 \pm 18.1$ & $<.0001$ \\
\hline Sex (No. of males, \%) & $312,55.6$ & $2060,46.9$ & 0.0001 \\
\hline Body Mass Index (kg/m^2) & $30.0 \pm 6.7$ & $28.6 \pm 6.7$ & $<.0001$ \\
\hline Total Cholesterol (mean \pm SD / mmol/L) & $4.79 \pm 1.23$ & $5.19 \pm 1.10$ & $<.0001$ \\
\hline \multicolumn{4}{|l|}{ Blood pressure (mean $\pm \mathrm{SD} / \mathrm{mmHg}$ ) } \\
\hline Systolic blood pressure & $132.5 \pm 23.1$ & $122.4 \pm 18.7$ & $<.0001$ \\
\hline Diastolic blood pressure & $68.7 \pm 14.9$ & $69.2 \pm 13.4$ & 0.5357 \\
\hline High blood pressure (N, \%) & $152,27.1$ & $628,14.3$ & $<.0001$ \\
\hline C-reactive protein $($ mean $\pm \mathrm{SD} / \mathrm{mg} / \mathrm{dL})$ & $0.68 \pm 1.14$ & $0.46 \pm 0.81$ & $<.0001$ \\
\hline Log10 (C-reactive protein) & $-0.50 \pm 0.55$ & $-0.68 \pm 0.56$ & $<.0001$ \\
\hline Homocysteine (mean \pm SD / umol/L) & $11.3 \pm 4.6$ & $8.1 \pm 4.5$ & $<.0001$ \\
\hline Log10 (Homocysteine) & $1.02 \pm 0.16$ & $0.88 \pm 0.16$ & $<.0001$ \\
\hline \multicolumn{4}{|l|}{ Smoke status (N, \%) } \\
\hline Current smoker & $104,18.5$ & $981,22.4$ & 0.4686 \\
\hline Past smoker & $229,40.8$ & $1020,23.3$ & $<.0001$ \\
\hline Alcohol status (N, \%) & $307,63.4$ & $2674,69.5$ & 0.0067 \\
\hline Diabetes (N, \%) & $168,31.2$ & $334,7.7$ & $<.0001$ \\
\hline \multicolumn{4}{|l|}{ Education level (N, \%) } \\
\hline High school and above & $356,63.5$ & $3202,73.1$ & $<.0001$ \\
\hline Race (N, \%) & & & $<.0001$ \\
\hline Non-Hispanic White & $343,61.1$ & $2137,48.7$ & $<.0001$ \\
\hline Non-Hispanic Black & $136,24.2$ & $984,22.4$ & 0.0010 \\
\hline Other Races & $82,14.6$ & $1271,28.9$ & $<.0001$ \\
\hline Family history of CVD (N, \%) & $121,22.6$ & $538,12.6$ & $<.0001$ \\
\hline $\begin{array}{l}\text { Serum total IgE concentrations (mean } \pm \text { SD } \\
/ \mathrm{kU} / \mathrm{L} \text { ) }\end{array}$ & $203.3 \pm 574.7$ & $158.7 \pm 466.4$ & 0.0962 \\
\hline Log10(total IgE) & $1.71 \pm 0.70$ & $1.68 \pm 0.65$ & 0.4012 \\
\hline High IgE level ( $\geq 175 \mathrm{kU} / \mathrm{L}, \mathrm{N}, \%)$ & $100,17.8$ & $770,17.5$ & 0.8634 \\
\hline \multicolumn{4}{|l|}{ Serum antigen-specific IgE } \\
\hline Negative specific $\operatorname{IgE}(\mathrm{N}, \%)$ & $387,69.0$ & $2568,58.5$ & $<.0001$ \\
\hline At least one positive specific $\operatorname{IgE}(\mathrm{N}, \%)$ & $174,31.0$ & $1824,41.5$ & $<.0001$ \\
\hline 1-6 positive specific IgE $(\mathrm{N}, \%)$ & $145,25.9$ & $1377,31.4$ & $<.0001$ \\
\hline$\geq 7$ positive specific $\operatorname{IgE}(\mathrm{N}, \%)$ & $29,5.2$ & $447,10.2$ & $<.0001$ \\
\hline Plant-related $\operatorname{IgE}(\mathrm{N}, \%)$ & $78,13.9$ & $1120,25.5$ & $<.0001$ \\
\hline Animal-related $\operatorname{IgE}(\mathrm{N}, \%)$ & $88,15.7$ & $905,20.6$ & 0.0061 \\
\hline Food-related $\operatorname{IgE}(\mathrm{N}, \%)$ & $78,13.9$ & $660,15.0$ & 0.4816 \\
\hline Mold-related IgE (N, \%) & $36,6.4$ & $417,9.5$ & 0.0173 \\
\hline Dust mite-related $\operatorname{IgE}(\mathrm{N}, \%)$ & $69,12.3$ & $882,20.1$ & $<.0001$ \\
\hline
\end{tabular}

\section{Association of total IgE with Coronary heart disease}

While using adjusted logistic regression model to analyze the relationship between total IgE level 
(Log10 transformed) and CHDs (see Supplement), we didn't detect any significant association of total $\operatorname{IgE}$ with CHDs and stroke.

Upon stratifying the analysis by different number of positive antigen-specific IgE tests, we noted a significant association of total IgE levels with CHDs when there were no positive antigen-specific IgE results, at least one and 1-6 positive specific $\operatorname{IgE}$ results with OR of $1.622(p=0.0250), 1.689(p=0.0337)$, and $2.098(p=0.0242)$, respectively (Table 2$)$. Total IgE levels were shown to be significantly associated with myocardial infarction (OR: 2.102; $p=0.0014$ ) when none of antigen-specific $\operatorname{IgE}$ results was positive. Significant association between total $\operatorname{IgE}$ and angina was also detected when at least one (OR: 2.505; $p=$ $0.0135)$ or 1-6 (OR: 2.948; $p=0.0103$ ) antigen-specific $\operatorname{IgE}$ test results were positive.

The association of total IgE levels with CVDs was further analyzed when antigen-specific IgEs were stratified into five different categories: plant, animal, food, mold and dust mite in adjusted logistic regression model (Table 3). Significant association of total IgE levels was noted with CHDs when food- or animal-specific $\operatorname{IgE}$ test results were positive (Food: OR 2.916, $p=0.0125$; Animal: OR 2.400, $p=0.0454$ ). Significant association of total IgE levels was noted with angina when dust mite-specific IgE test results were positive (OR: 4.923, $p=0.0310$ ). However, an inverse relation of total $\mathrm{IgE}$ levels and myocardial infarction was found when plant-specific $\operatorname{IgE}$ test results were positive (OR: 0.307, $p=0.0433$ ).

\section{Association of total IgE with stroke}

Upon stratifying the analysis by different number of positive antigen-specific $\operatorname{IgE}$ tests or different categories of antigen-specific IgE, we noted no significant association of total $\mathrm{IgE}$ levels with stroke (Table 2 and Table 3).

\section{Association of antigen-specific IgE with myocardial infarction}

As is stated above, an inverse relation of total $\operatorname{IgE}$ levels and myocardial infarction was found when plant-specific IgE test results were positive (OR: 0.307, $p=0.0433$; Table 3). We further analyzed the relationship between the whole 19 antigen-specific IgE and myocardial infarction. As shown in Table 4, oak-, birch-, and peanut-specific IgE levels were all inversely related to myocardial infarction.

\section{Discussion}

In this cross-sectional study among US population aged over 20, we analyzed the relationship between serum antigen-specific and total $\operatorname{IgE}$ with doctor-diagnosed CVDs using logistic regression model. Our results showed: 1) Coronary heart disease had significant association with serum total $\operatorname{IgE}$ with stratification by the numbers of positive antigenspecific IgEs. With the increase in numbers of positive antigen-specific IgE, the ORs became higher, suggesting that total $\operatorname{IgE}$ was more closely related to coronary heart disease (see Table 2). 2) Myocardial infarction was found to be positively related to serum total IgE levels only when all antigen-specific IgE test results were negative. By contrast, myocardial infarction was inversely associated with serum total IgE levels when plant-specific IgE test results were positive. Moreover, myocardial infarction was also inversely related to positive oak, birch, or peanut-specific IgE (see Table 2, 3 and 4). 3) Among 19 antigen-specific IgE, angina was directly associated with serum total IgE level only when dust mite-specific IgE test results were positive (see Table 3). 4) In addition, when food-specific IgE test results were positive, serum total IgE levels were directly related to CVDs as a whole (see Table 3).

Table 2. Logistic regression analysis of association of Log10(total $\lg \mathrm{E}$ ) with CVDs stratified by the numbers of allergen-specific lgE.

\begin{tabular}{|c|c|c|c|c|}
\hline Classification of CVD & OR $(95 \% \mathrm{CI})$ & p value & OR $(95 \%$ CI) & p value \\
\hline & \multicolumn{2}{|c|}{ Negative specific IgE result } & \multicolumn{2}{|c|}{$\geq 1$ positive specific IgE results } \\
\hline Coronary heart disease & $1.622(1.072-2.455)$ & 0.0250 & $1.689(1.047-2.726)$ & 0.0337 \\
\hline Myocardial infarction & $2.102(1.403-3.147)$ & 0.0014 & $1.080(0.513-2.274)$ & 0.8276 \\
\hline Angina & $1.175(0.714-1.935)$ & 0.5003 & $2.505(1.244-5.041)$ & 0.0135 \\
\hline Stroke & $0.830(0.436-1.582)$ & 0.5481 & $0.790(0.406-1.538)$ & 0.4624 \\
\hline \multirow[t]{2}{*}{ CVDs } & $1.346(0.965-1.877)$ & 0.0760 & $1.341(0.839-2.142)$ & 0.2021 \\
\hline & \multicolumn{2}{|c|}{ 1-6 positive specific IgE results } & \multicolumn{2}{|c|}{$\geq 7$ positive specific IgE results } \\
\hline Coronary heart disease & $2.098(1.117-3.940)$ & 0.0242 & $1.444(0.523-3.987)$ & 0.4532 \\
\hline Myocardial infarction & $1.627(0.571-4.629)$ & 0.3373 & - & * \\
\hline Angina & $2.948(1.343-6.470)$ & 0.0103 & - & * \\
\hline Stroke & $0.802(0.316-2.034)$ & 0.6203 & $1.018(0.345-3.005)$ & 0.9722 \\
\hline CVDs & $1.414(0.845-2.369)$ & 0.1722 & $1.501(0.625-3.607)$ & 0.3393 \\
\hline
\end{tabular}

Note: * The maximum likelihood estimate does not exist due to a complete separation of data points. Adjusted by age, gender, race, education level, diabetes mellitus, hypertension, family history of CVD, smoking status, alcohol status, BMI, serum TC, homocysteine and CRP levels. Abbreviations: CVD: cardiovascular disease; OR: odds ratio; CI: confidence interval. 
Table 3. Logistic regression analysis of association of Log 10(total $\mathrm{IgE})$ with CVDs stratified by different categories of antigen-specific $\lg \mathrm{E}$.

\begin{tabular}{llr}
\hline Classification of CVD & OR $(95 \%$ CI $)$ & p value \\
\hline & Positive food-specific IgE & \\
Coronary heart disease & $2.916(1.305-6.517)$ & $\mathbf{0 . 0 1 2 5}$ \\
Myocardial infarction & $4.006(0.255-62.988)$ & 0.2999 \\
Angina & $2.152(0.592-7.825)$ & 0.2250 \\
Stroke & $1.797(0.540-5.980)$ & 0.3150 \\
CVDs & $2.232(1.154-4.317)$ & $\mathbf{0 . 0 2 0 4}$ \\
& Positive animal-specific IgE & \\
Coronary heart disease & $2.400(1.021-5.642)$ & $\mathbf{0 . 0 4 5 4}$ \\
Myocardial infarction & $0.815(0.282-2.353)$ & 0.6872 \\
Angina & $2.952(0.955-9.128)$ & 0.0590 \\
Stroke & $0.849(0.372-1.936)$ & 0.6778 \\
CVDs & $1.721(0.775-3.822)$ & 0.1676 \\
& Positive dust mite-specific IgE \\
Coronary heart disease & $2.574(0.793-8.358)$ & 0.1076 \\
Myocardial infarction & $0.433(0.067-2.809)$ & 0.3550 \\
Angina & $4.923(1.182-20.512)$ & $\mathbf{0 . 0 3 1 0}$ \\
Stroke & $0.630(0.221-1.798)$ & 0.3622 \\
CVDs & $1.759(0.722-4.286)$ & 0.1964 \\
& Positive plant-specific IgE & \\
Coronary heart disease & $0.994(0.301-3.280)$ & 0.9909 \\
Myocardial infarction & $0.307(0.098-0.960)$ & $\mathbf{0 . 0 4 3 3}$ \\
Angina & $2.512(0.620-10.182)$ & 0.1811 \\
Stroke & $0.562(0.289-1.094)$ & 0.0852 \\
CVDs & $0.996(0.356-2.789)$ & 0.9936 \\
\hline Note: Positive category-specis & IgE & \\
\hline
\end{tabular}

Note: Positive category-specific IgE result was defined as at least one positive antigen-specific IgE in this category. Total IgE didn't show any significant association with CVDs when mold- specific IgE was positive (see Supplement). Adjusted by age, gender, race, education level, diabetes mellitus, hypertension, family history of CVD, smoking status, alcohol status, BMI, serum TC, homocysteine and CRP levels. Abbreviations: CVD: cardiovascular disease; OR: odds ratio; CI: confidence interval.

Table 4. Logistic regression analysis of association of antigen-specific lgE with myocardial infarction.

\begin{tabular}{|c|c|c|c|}
\hline Antigen-specific IgEs & OR & $95 \% \mathrm{CI}$ & $p$ value \\
\hline $\begin{array}{l}\text { Number of positive antigen-specific } \operatorname{IgE} \\
(\mathrm{N}=0-19)\end{array}$ & 0.846 & $0.736-0.972$ & 0.0211 \\
\hline Oak-specific IgE & 0.074 & $0.048-0.116$ & $<.0001$ \\
\hline Birch-specific IgE & 0.075 & $0.046-0.120$ & $<.0001$ \\
\hline Peanut-specific $\operatorname{IgE}$ & 0.106 & $0.043-0.262$ & $<.0001$ \\
\hline
\end{tabular}

Previous cross-sectional studies reported significant increased levels of serum IgE in patients with coronary heart disease compared to those in healthy controls $8,11,16,18$. A prospective clinical study with a mean follow-up of 8.9 years, showed the serum IgE levels significantly higher in patients with ischemic heart disease than in those who did not ${ }^{14}$. Our study, for the first time, reported that total $\operatorname{IgE}$ was related to coronary heart disease only when adjusted by the numbers of positive antigen-specific $\operatorname{IgE}$, and the strength of the association increased with the accumulation of positive antigen-specific IgEs. As for the categories of antigen-specific IgEs, total IgE was related to coronary heart disease only when foodor animal-specific IgEs were positive. In addition, the relationship changed with different subgroups of
CVDs. Therefore, our study provided new details for the complex and subtle relationships between CVDs with serum total or antigen-specific IgEs. The numbers and categories of positive antigen-specific IgEs may determine different relationships between them, which indicates more important role of specific antigens in mechanism of CVDs. Future studies may further subdivide antigens and clarify mechanism of each antigen-specific IgE in each CVDs and also more specially designed studies to confirm our results.

IgE might not always be a risk factor for CVDs, which many people might take it for granted. A previous cross-sectional study by Jaramillo et al reported that positive specific IgE test results were inversely related with myocardial infarction ${ }^{19}$. Our study found that total $\operatorname{IgE}$ was inversely related to myocardial infarction only when plant-specific IgEs were positive. Further analysis found three plant-specific IgEs (oak-, birch-, or peanut-specific IgEs) had inverse relationships with myocardial infarction, which indicates these plant-specific IgEs might be a protective factor for myocardial infarction. On the other hand, total IgE was positively related to myocardial infarction only when all antigen-specific IgEs were negative, which, in this case, indicates IgE might be a risk factor. After all, the causality between them is still unclear, so it is too early to discuss whether IgE is a risk or protective factor for myocardial infarction. Therefore, future prospective studies or animal studies are required to clarify the causality and this controversy.

A study among 209 Turkish population found that serum total IgE levels were significantly higher in patients with unstable angina compared to those in patients with stable angina pectoris and controls ${ }^{11}$. In the present study, we first demonstrated that serum total IgE levels were directly associated with angina when dust mite-specific IgE test results were positive, suggesting an important role of dust mite-specific $\operatorname{IgE}$ in the relationship of angina with serum total IgE. In addition, serum total IgE levels were also found to be directly related to CVDs as a whole when food-specific IgE test results were positive. Stroke, however, didn't show any significant relation with total or antigen-specific IgEs. Although recent studies reported IgE might have a certain role in stroke 20, 21, more studies are still needed.

There were several facts supporting a potential mechanism for the relationships of serum total $\operatorname{IgE}$ levels to coronary heart disease, and plant-specific IgE to myocardial infarction. The biological activity of $\operatorname{IgE}$ depends on its binding to Fc receptors presented on the surface of mast cells, basophiles, and monocytes ${ }^{22}$. First, both in vitro and animal model experiments showed the binding of $\operatorname{IgE}$ to mast cells would 
stimulate the release of several inflammatory mediators such as tromboxanes, leukotrienes, histamine and tryptase ${ }^{23-26}$. These inflammatory mediators actively contribute to the preceding development of atherosclerotic plaque, the process of its destabilization and subsequent erosion or rupture as well ${ }^{27-30}$. Second, IgE could activate monocytes, macrophages or other types of immune cells to facilitate the pathogenesis of atherosclerosis, by binding to the high-affinity $\operatorname{IgE}$ receptor and toll-like receptor 4 16, 31. Last but not the least, the close locations of two genes affecting atheromatous plaque formation and total serum IgE concentrations may be a possible explanation of the relationship between total $\operatorname{IgE}$ and coronary heart disease ${ }^{32-34}$. Future studies focusing on the role of antigen-specific $\operatorname{IgE}$ in the mechanism of development of atherosclerosis and CVDs are needed.

The seemingly paradox of plant-specific and non-plant-specific IgEs to myocardial infarction discussed above is similar to the relationship of HDL-C, non-HDL-C (LDL-C), and TC to myocardial infarction, proposed by Jaramillo et al. ${ }^{19}$. This could be explained by the mutually antagonism of Th1/Th2 immune programs ${ }^{35}$. As we are acknowledged, human atherosclerotic vascular disease is Th1-predominant and positively associated with total $\operatorname{IgE}{ }^{36}$. Same as total $\operatorname{IgE}$, some antigen-specific $\operatorname{IgE}$ also binds to FceR promoting vascular injury and atheromatous plaque formation. Nevertheless, certain antigen-specific IgE may simultaneously track with IL4, the master regulators of atheroprotective Th2 programming to antagonize Th1 immunity 19. Different antigen-specific IgEs might adopt different pathways to contribute to the development of myocardial infarction. Due to the low prevalence of antigen-specific $\operatorname{IgE}$, this is a possible speculation of the potential mechanism. Future investigation is warranted.

Strengths of the study include a large, nationally representative sample of target population with a large number of potential confounders available with the database NHANES 2005-2006, meanwhile, the cross-sectional analysis lack evidences of causality, directionality, and temporality of the IgE-CHDs relationship. Does IgE result in or from CHDs? The possibility of reverse causation cannot be excluded. In addition, since low-income subjects, African Americans and Mexican Americans were oversampled among others in the NHANES 2005-2006, possible population selection bias cannot be excluded. Furthermore, self-reported questionnaire for CHDs may carry risk of introducing bias, exaggerating a positive association between $\operatorname{IgE}$ and CHDs. However, reports from NHANES indicate good validity of self-reported CHDs ${ }^{37}$, also indicating good validity of our analysis.

In conclusion, we have identified significant association of serum antigen-specific and total IgE levels with CVDs independently of a long list of established cardiovascular risk factors. We also provide valuable information on the potential of antigen-specific IgE in clinical CVD risk, and possible protective role of plant antigen-specific IgEs in myocardial infarction. As levels of antigen-specific IgE are more informative than levels of total IgE per se, future large-scale, multi-center, longitudinal perspective studies are warranted to further explore the association of antigen-specific IgE and CVDs.

\section{Supplementary Material}

Supplementary table.

http://www.medsci.org/v15p1098s1.pdf

\section{Acknowledgements}

The authors would like to thank Dr. Xuguang Guo for his valuable advice for setting up the initial idea and technical assistance in statistical analysis.

The article was supported by national grants as follows: National Natural Science Foundation of China \# 81470579 (Jing Wang), Henry Fok Education Fund \#151040 (Jing Wang), the IBMS/CAMS Dean's Fund \#2011RC01 (Chao Ma), and Hundred Talents Program of the Chinese Academy of Sciences (Yi Hu).

\section{Competing Interests}

The authors have declared that no competing interest exists.

\section{References}

1. WHO. Cardiovascular diseases (CVDs). Vol Fact sheet $\mathrm{N}^{\circ} 317$. Updated January 2015 ed: World Health Organization; 2015.

2. Laslett LJ, Alagona P, Jr., Clark BA, 3rd, et al. The worldwide environment of cardiovascular disease: prevalence, diagnosis, therapy, and policy issues: a report from the American College of Cardiology. J Am Coll Cardiol. 2012;60:S1-49.

3. Patel SA, Winkel M, Ali MK, Narayan KM, Mehta NK. Cardiovascular mortality associated with 5 leading risk factors: national and state preventable fractions estimated from survey data. Annals of internal medicine. 2015;163:245-253.

4. Yusuf S, Hawken S, Ounpuu S, et al. Effect of potentially modifiable risk factors associated with myocardial infarction in 52 countries (the INTERHEART study): case-control study. Lancet (London, England). 2004;364:937-952.

5. Vasan RS, Sullivan LM, Wilson PW, et al. Relative importance of borderline and elevated levels of coronary heart disease risk factors. Annals of internal medicine. 2005;142:393-402.

6. Stamler J, Stamler R, Neaton JD, et al. Low risk-factor profile and long-term cardiovascular and noncardiovascular mortality and life expectancy: findings for 5 large cohorts of young adult and middle-aged men and women. Jama. 1999;282:2012-2018.

7. Pate MB, Smith JK, Chi DS, Krishnaswamy G. Regulation and dysregulation of immunoglobulin E: a molecular and clinical perspective. Clinical and molecular allergy : CMA. 2010;8:3.

8. Criqui MH, Lee ER, Hamburger RN, Klauber MR, Coughlin SS. IgE and cardiovascular disease. Results from a population-based study. The American journal of medicine. 1987;82:964-968.

9. Buyukberber S, Sencan O, Buyukberber N, et al. Serum immunoglobulin E (Ig E) levels after myocardial infarction. Acta cardiologica. 1997;52:335-345. 
10. Criqui MH. Serum immunoglobulin $\mathrm{E}$ after myocardial infarction. Circulation. 1988;78:1322.

11. Korkmaz ME, Oto A, Saraclar Y, et al. Levels of IgE in the serum of patients with coronary arterial disease. International journal of cardiology. 1991;31:199-204.

12. Ling JC, Freeman AF, Gharib AM, et al. Coronary artery aneurysms in patients with hyper IgE recurrent infection syndrome. Clinical immunology (Orlando, Fla.). 2007;122:255-258.

13. Magen E, Mishal J, Vardy D. Selective IgE deficiency and cardiovascular diseases. Allergy and asthma proceedings: the official journal of regional and state allergy societies. 2015;36:225-229.

14. Langer RD, Criqui MH, Feigelson HS, McCann TJ, Hamburger RN. IgE predicts future nonfatal myocardial infarction in men. Journal of clinical epidemiology. 1996;49:203-209.

15. Guo X, Yuan S, Liu Y, et al. Serum IgE levels are associated with coronary artery disease severity. Atherosclerosis. 2016.

16. Wang J, Cheng $X$, Xiang MX, et al. IgE stimulates human and mouse arterial cell apoptosis and cytokine expression and promotes atherogenesis in Apoe-/mice. The Journal of clinical investigation. 2011;121:3564-3577.

17. Shiue I. Are higher serum IgE concentrations associated with adult cardiovascular disease? International journal of cardiology. 2013;168:1580-1581.

18. Sinkiewicz W, Blazejewski J, Bujak R, Kubica J, Dudziak J. Immunoglobulin E in patients with ischemic heart disease. Cardiology journal. 2008;15:122-128.

19. Jaramillo R, Cohn RD, Crockett PW, Gowdy KM, Zeldin DC, Fessler MB. Relation between objective measures of atopy and myocardial infarction in the United States. The Journal of allergy and clinical immunology. 2013;131:405-411.e401-411.

20. Nojima $Y$, Ihara M, Kurimoto T, Nanto S. Amyloid Light-Chain Amyloidosis Manifesting as Heart Failure with Preserved Ejection Fraction in a Patient with Hyper-Immunoglobulin E-emia. The American journal of case reports. 2016;17:235-240

21. Guo R, Liu H, Li M, et al. Cerebral arteriostenosis associated with elevated serum-immunoglobulin $\mathrm{E}$ level in young adults without risk factors for ischemic stroke: a possible manifestation of cerebral vasculitis? Journal of clinical neuroscience : official journal of the Neurosurgical Society of Australasia. 2014;21:95-99.

22. Kinet JP. The high-affinity IgE receptor (Fc epsilon RI): from physiology to pathology. Annual review of immunology. 1999;17:931-972.

23. Potaczek DP. Links between allergy and cardiovascular or hemostatic system. International journal of cardiology. 2014;170:278-285.

24. Takase B, Maruyama T, Kurita A, et al. Arachidonic acid metabolites in acute myocardial infarction. Angiology. 1996;47:649-661.

25. Clejan S, Japa S, Clemetson C, Hasabnis SS, David O, Talano JV. Blood histamine is associated with coronary artery disease, cardiac events and severity of inflammation and atherosclerosis. Journal of cellular and molecular medicine. 2002;6:583-592.

26. Filipiak KJ, Tarchalska-Krynska B, Opolski G, et al. Tryptase levels in patients after acute coronary syndromes: the potential new marker of an unstable plaque? Clinical cardiology. 2003;26:366-372.

27. Kovanen PT. Mast cells: multipotent local effector cells in atherothrombosis. Immunological reviews. 2007;217:105-122.

28. Sun J, Sukhova GK, Wolters PJ, et al. Mast cells promote atherosclerosis by releasing proinflammatory cytokines. Nature medicine. 2007;13:719-724.

29. Libby P, Shi GP. Mast cells as mediators and modulators of atherogenesis. Circulation. 2007;115:2471-2473.

30. Weber C, Zernecke A, Libby P. The multifaceted contributions of leukocyte subsets to atherosclerosis: lessons from mouse models. Nature reviews immunology. 2008;8:802-815.

31. Binder CJ, Witztum JL. Is atherosclerosis an allergic disease? Circulation research. 2011;109:1103-1104

32. Potaczek DP, Kabesch M. Current concepts of IgE regulation and impact of genetic determinants. Clinical and experimental allergy: journal of the British Society for Allergy and Clinical Immunology. 2012;42:852-871.

33. Potaczek DP, Okumura K, Nishiyama C. FCER1A genetic variability and serum IgE levels. Allergy. 2009;64:1383.

34. Benjamin EJ, Dupuis J, Larson MG, et al. Genome-wide association with select biomarker traits in the Framingham Heart Study. BMC Med Genet. 2007;8 Suppl 1:S11.

35. Schulte S, Sukhova GK, Libby P. Genetically programmed biases in Th1 and Th2 immune responses modulate atherogenesis. The American journal of pathology. 2008;172:1500-1508.

36. Huber SA, Sakkinen P, David C, Newell MK, Tracy RP. T helper-cell phenotype regulates atherosclerosis in mice under conditions of mild hypercholesterolemia. Circulation. 2001;103:2610-2616.

37. Bergmann MM, Byers T, Freedman DS, Mokdad A. Validity of self-reported diagnoses leading to hospitalization: a comparison of self-reports with hospital records in a prospective study of American adults. American journal of epidemiology. 1998;147:969-977. 